\title{
COMO SE CHEGA A SER O QUE SE É: FORMAÇÃO- EXPERIÊNCIA COMO ATITUDE DESPOSSÍVEL NA PRODUÇÃO DE SUBJETIVIDADES TILSP
}

\author{
Lucyenne Matos da Costa Vieira-Machado 1 \\ Cassio Pereira Oliveira 1 \\ ${ }^{1}$ Universidade Federal do Espírito Santo, Vitória, Espírito Santo, Brasil
}

\begin{abstract}
Resumo: Este artigo tem como objetivo analisar e problematizar como, no processo formativo, vêm sendo constituídas as tecnologias de modulação nas condutas dos Tradutores e Intérpretes de Libras-Português. Assim, intentamos olhar para a formação como tema a partir de uma perspectiva ética e estética, decompondo seu conceito a partir dos processos de sujeição, bem como as linhas de fugas que produzem subjetividades específicas. A formação aqui discutida não é a possível e nem a impossível, mas uma formação com a justaposição da palavra experiência como uma despossibilidade. Como procedimento teórico-metodológico, utilizamos as conversas, de forma on-line devido ao isolamento social imposto pela pandemia mundial que estamos vivendo, com 122 TILSP de todos as regiões do Brasil. $\mathrm{Na}$ análise dos dados, trabalhamos com as quatro figuras subjetivas da crise de Hardt e Negri (2014), a saber: TILSP endividado, mediatizado, securitizado e representado. Como recorte dos resultados desta pesquisa, neste artigo, escolhemos o TILSP securitizado para problematizar e decompor o conceito de formação e nas vozes ecoadas nas conversas com os diferentes TILSP dos diferentes espaços/lugares a formação-experiência, então, torna-se um caminhar em direção do encontro das diferentes singularidades, produzindo, assim, sujeitos-potências capazes de rebelar-se e produzirem-se em figuras de poder a partir de subjetividades outras não nomeadas.
\end{abstract}

Palavras-chave: Formação; Tradutor e Intérprete de Libras-Português; Experiência 


\title{
HOW DO YOU BECOME WHAT YOU ARE? EDUCATION- EXPERIENCE AS AN UNPOSSIBLE ATTITUDE IN THE PRODUCTION OF TILSP SUBJECTIVITIES
}

\begin{abstract}
This article aims to analyze and discuss how, in the training process, modulation technologies arise through the conduct of the LibrasPortuguese Translators and Interpreters (TILSP). Thus, we try to thematically look at training from an ethical and aesthetic perspective, breaking down its concept from the processes of subjection, as well as the escape lines that produce specific subjectivities. The training discussed here is not possible nor impossible, but the one that arises through the juxtaposition of the word experience as an un-possibility. As a theoretical-methodological procedure, we relied on online meetings with 122 TILSP of all regions of Brazil, due to the social distancing measures imposed by the global pandemic in which we are living. In the data analysis, we work with the four subjective figures of the Hardt and Negri crisis (2014), namely: indebted, mediatized, securitized, and represented TILSP. As a conclusion, in this article, we chose the securitized TILSP to problematize and decompose the concept of formation in the voices echoed in conversations with different TILSP from different spaces/places. The training-experience then becomes a journey towards the encounter of different singularities, thus producing subjectpowers capable of rebelling and producing themselves in figures of power from other unnamed subjectivities.
\end{abstract}

Keywords: Education; Libras-Portuguese Translator and Interpreter; Experience

\section{Sobre a estrutura de uma bolha de sabão...}

Era o que ele estudava. "A estrutura, quer dizer, a estrutura", ele repetia e abria a mão branquíssima ao esboçar o gesto redondo.

Eu ficava olhando seu gesto impreciso porque uma bolha de sabão é mesmo imprecisa, nem sólida nem líquida, nem realidade nem sonho. Película e oco.

"A estrutura da bolha de sabão, compreende?" (Lygia Fagundes Telles)

Cad. Trad., Florianópolis, v. 41, n $^{0}$ esp. 2, p. 273-302, ago/dez, 2021. 274 
Este texto é sobre formação. Formação de Tradutores e Intérpretes do par linguístico Libras e Língua Portuguesa (TILSP). É sobre a despossibilidade de uma formação ética e estética criadora de realidades e vidas outras no exercício profissional. É sobre olhar para a formação a partir do par experiência e sentido (Larrosa 151).

Não é sobre olhar para a formação a partir dos pares clássicos: teoria e prática ou técnica e ciência. Outros tantos trabalhos fazem isso de forma primorosa e com muito sucesso. Este texto é sobre outra coisa e, para lograr êxito nesta aposta, faz-se necessário colocar a palavra formação hifenizada com a palavra experiência, ou seja, formação-experiência.

Ao ler a obra de Lygia Fagundes Telles, intitulada $A$ estrutura da bolha de sabão, fomos atravessados pela contradição da ideia da solidez de uma estrutura, bem como a fugacidade da película da bolha de sabão. Retomando a epígrafe, a bolha de sabão é imprecisa, nem sólida, nem líquida e nem gasosa, enfim, não é possível e nem impossível e aqui, neste texto, intentamos olhar para a formação maior ${ }^{1}$, institucional e modulada como se ela apresentasse a estrutura de uma bolha de sabão, decompondo-a lentamente tanto nos processos de sujeição quanto nas linhas de fugas produzidas. A formação aqui discutida não é a possível e nem a impossível; é como uma bolha de sabão, despossível.

O filme Alice através do espelho (2016), do diretor James Bobin, apresenta uma fala que não está contida no livro original de autoria de Lewis Carroll. A fala é encontrada nessa adaptação cinematográfica, e a cena, que se passa nos primeiros minutos do filme, é composta por um mapeamento da trama que conduzirá todo o filme, qual seja, a viagem de retorno ao tempo que a personagem Alice deverá fazer para salvar a família do seu amigo Chapeleiro. Após saber que a condição para a melhora do Chapeleiro

\footnotetext{
1 Neste artigo, a ideia de formação maior está relacionada às formações institucionais, oficiais baseadas em modulações de como ser Tilsp de forma específica. A ideia de formação menor está relacionada a possibilidades outras de formação que não passam pelas institucionais.
}

Cad. Trad., Florianópolis, v. 41, $\mathrm{n}^{0}$ esp. 2, p. 273-302, ago/dez, 2021. 275 
era o retorno da sua família, supostamente morta no passado, Alice prontamente se vê numa situação limite que pode ser verificada quando diz: "Mas isso não é possível!". A rainha, no entanto, sugere que retornar ao tempo, embora fosse "arriscado, perigoso e pedir muito", se configurava como a maneira de executar a missão. O diálogo finaliza com o Gato verbalizando que esse trajeto de retorno ao tempo "não é (possível e nem) impossível... meramente... despossivel". ${ }^{2}$

A partir do despossível, a noção de formação que temos como base para desenvolver este trabalho precisou ser construída através de uma aproximação com a noção de experiência. No caso da formação, um recuo histórico foi necessário para elucidar as regularidades e as descontinuidades que operaram, no decorrer da história, fabricando modos específicos de relação com a ideia de formação, bem como os limites por ela impostos.

Esse exercício se aproxima da ideia de mapear as práticas que constituem a formação dos Tradutores e Intérpretes de Libras-Português e, ao nos depararmos com as (im)possibilidades/limites impostas por essa formação, recorremos à noção de experiência como modo de pensar o embate agonístico entre aporia e liberdade. Argumentamos que, ao compreender/questionar tais noções, forjamos descontinuidades que produzem tipos de sujeitos que agem de maneiras múltiplas, que se sobrepõem numa relação, inscritas numa racionalidade específica, bem como produzem ações que se constroem de formas, sempre, provisórias, ou, em direções nunca estanques. Antes de discorrer sobre a noção de formação-experiência, que anunciamos logo no título deste texto, consideramos prudente antecipar que essa díade emerge de conversas ou, poderíamos assim dizer, de práticas de conversação produzidas como procedimento metodológico em encontros que julgamos merecer atenção.

Este artigo é um recorte de parte dos resultados de uma pesquisa intitulada "Formação-experiência como um caminho despossível

${ }^{2}$ Tradução do inglês: "It's not impossibel... merely... un-possibel" (Alice através do espelho, do diretor James Bobin 2016).

Cad. Trad., Florianópolis, v. 41, $\mathrm{n}^{0}$ esp. 2, p. 273-302, ago/dez, 2021. 276 
para tradutores e intérpretes de libras-português” que está inserida no projeto maior, intitulado "Tradutores/ Intérpretes de Línguas de Sinais: políticas, práticas e processos de formação no ensino superior", realizado em parceria com outros grupos de pesquisa, pensando diferentes rotas formativas e incluindo, por meio de projeto de internacionalização: formação de TILSP Brasil/ México.

A pesquisa tem como objetivos centrais, dentre outros, analisar e problematizar como, no processo formativo, vêm sendo constituídas as tecnologias de modulação nas condutas dos TILSP; e a partir das conversas com eles, como se constituem nas tecnologias de modulação de condutas correlatas a uma racionalidade política moderna, bem como formas de ser TILSP que se configuram como linhas de fuga. Assim, a partir dessas primeiras informações, abrimos o novelo destacando pontos importantes do percurso teóricometodológico, num primeiro momento. Posteriormente, discutiremos uma parte dos resultados recortados para este texto.

\section{Ainda sobre uma bolha de sabão: precisão e imprecisão da estrutura de uma formação}

O que é ser TILSP? Quais conhecimentos são essenciais para os profissionais que atuam com esse par linguístico? Quem não tem formação pode atuar como TILSP? O que estamos chamando de formação ou "A" formação que autoriza a atuação como TILSP?

A partir do exercício de decomposição da palavra formação, a tese que defendemos, nesse trabalho, é a de que a formação-experiência é uma atitude cuja característica potencializa modos de ser TILSP através de experimentações menores ${ }^{3}$ existentes no cotidiano e inscritas no aqui e agora. Experimentar modos de constituição

\footnotetext{
${ }^{3}$ Neste texto, quando tratamos de formação menor, estamos falando sobre os processos formativos individuais e quase como um autodidatismo que nesta pesquisa percebemos proliferados nas práticas dos tilsp principalmente quando as formações institucionais como o Letras Libras bacharelado chegam em todos os lugares do Brasil.
}

Cad. Trad., Florianópolis, v. 41, $\mathbf{n}^{0}$ esp. 2, p. 273-302, ago/dez, 2021. 277 
foi um movimento que, paradoxalmente ao cenário/contexto em que vivemos (de privação de nossas capacidades humanas, sobretudo a de ação política), estamos diante de um tempo oportuno (kairós), quando a cooperação e a interdependência produtiva são as condições do comum.

Deste modo, nesse kairós, constituímos modos de existência éticos que alargam nosso grau de liberdade, e a experiência, nesse sentido, é tomada como algo que pode e deve ser (re)pensada, capaz de nos separar de nós mesmos e mudar a maneira como pensamos e agimos. Nesse movimento, como resultado dessa pesquisa, a formação-experiência se configura como um vetor para pensar os TILSP como sujeitos capazes de subverter os processos que reproduzem figuras de subjugação.

A junção desses dois conceitos nos/se inscreve numa rede de sujeitos que se configuram como um coletivo intitulado Grupo Interinstitucional de Pesquisas em Libras e Educação de Surdos (Giples). Mais especificamente, naqueles espaços formativos não institucionalizados como um bom café na cantina da universidade, por exemplo, onde tudo começou. Quando surge a ideia dessa noção de justaposição de formação com experiência, formação-experiência, o objetivo expresso era ampliar de forma significativa a discussão da formação ética, haja vista que, na área das discussões sobre formação de TILSP, essa temática ainda é, de certo modo, embrionária. Essa noção começa a nos atravessar como uma forma de revisitar aquilo que temos pensado acerca da noção de formação (de TILSP) como um passo que compõe o(s) trajeto(s) de retorno a nós mesmos, um passo sobre o qual pensamos a nossa constituição enquanto profissionais.

Neste trabalho, a experiência justaposta à formação se relaciona com o conceito de experimentação. As experimentações são tomadas como vetor que potencializa a vida. Deleuze nos diz: "Experimente, mas é preciso muita prudência para experimentar" (Deleuze and Parnet 50).

A experimentação, portanto, como processo constituinte da vida, é evocada quando o pensamento de Guattari é descrito como

Cad. Trad., Florianópolis, v. 41, $\mathbf{n}^{0}$ esp. 2, p. 273-302, ago/dez, 2021. 278 
uma "espécie de rodeio selvagem, em parte contra ele próprio" (Deleuze and Parnet 10). Os autores, assim, consideram que "a experimentação sobre si mesmo é nossa única identidade, nossa única chance para todas as combinações que nos habitam. [...] vocês não são mestres, mas são ainda mais sufocantes" (Deleuze and Parnet 10).

A noção de formação se aproximou, num primeiro momento, de uma definição da palavra Bildung. Justificamos que o uso desse conceito nos é útil para descrever sua descontinuidade ao mesmo tempo em que argumentamos a constituição de um ethos de formação diretamente ligado ao conceito de experiência. A Bildung, analisada a partir de um ponto de vista pedagógico, é descrita da seguinte forma:

O que é então a Bildung? Ao mesmo tempo um processo e seu resultado. Pela Bildung, um indvíduo, um povo, uma nação, mas também uma língua, uma literatura, uma obra de arte em geral se formam e adquirem, assim, uma forma, uma Bild. A Bildung é sempre um movimento em direção a uma forma, a forma que é uma forma própria. (Berman 80).

A Bildung é descrita como processo temporal e, portanto, histórico.

Nesse sentido, a Bildung é um auto-processo em que há um mesmo que se desdobra até adquirir sua plena dimensão. É provável que o conceito mais elevado [...] para interpretar esse processo seja o da experiência. [...] Pois a experiência é a única noção que pode abraçar todas as outras. [...] Sua essência é jogar o "mesmo" em uma dimensão que vai transformá-lo. Ela é o movimento do "mesmo" que, mudando, encontra-se "outro". (Berman 81-2).

Cad. Trad., Florianópolis, v. 41, $\mathbf{n}^{0}$ esp. 2, p. 273-302, ago/dez, 2021. 279 
A revisita ao pensamento, associada às noções de tempo, formação e experiência, nos oportunizaram caminhos outros na discussão sobre formação. Impossível ou possível? A aproximação dessas noções nos trouxe à justaposição formação-experiência como um caminho despossível para a formação de TILSP. De maneira paradoxal, o uso do prefixo "des-" na Língua Portuguesa, bem como o uso do prefixo $u n{ }^{-}{ }^{4}$ na Língua Inglesa, traz a ideia de negação ou oposição e a de reverter uma ação através do uso.

Somos travessos quando propomos, em nossa decomposição, o caminhar com a justaposição formação-experiência. Essa pequena peraltice foi necessária a nós mesmos quando propomos um deslocamento do modo de pensar "A" formação.

\subsection{A flutuação da bolha: percursos teórico-metodológicos}

A partir das "lições aprendidas com Foucault" (Fischer 100), Fischer chama de "atitudes metodológicas" alguns direcionamentos necessários ao pesquisador e os divide em três.

$\mathrm{Na}$ primeira atitude, a autora afirma que as pesquisas e as lutas estão sempre relacionadas à linguagem, "já que estamos continuamente envolvidos com lutas discursivas" (Fischer 100). Na segunda, ainda de acordo com o mesmo texto, devemos "atentar para ideia de que palavras e coisas dizem respeito a fatos e enunciados" e que, embora possam parecer óbvios, possuem, como comento posteriormente, um "efeito de raridade" (Deleuze 14). Na terceira atitude, é necessário observar que "fatos e enunciados referem-se basicamente a práticas, discursivas e não discursivas, as quais constituem a matéria-prima das nossas investigações" (Fischer 100).

A partir dessas atitudes, é fundamental apresentar o rigor metodológico por meio dos procedimentos adotados para que essa pesquisa se efetivasse. Pensar munido dessas atitudes não necessariamente significa ir para fora de uma produção de formas pelas

\footnotetext{
${ }^{4}$ No inglês, o prefixo "un-" não é utilizado antes de palavras que começam com p. Nesse caso, o neologismo se constitui duplamente nas duas línguas.
}

Cad. Trad., Florianópolis, v. 41, $\mathrm{n}^{0}$ esp. 2, p. 273-302, ago/dez, 2021. 280 
quais nos tornamos TILSP, pois é a partir do plano da imanência que os dados foram produzidos.

Ao tratar da formação de TILSP no nosso tempo, tomamos a conversa como uma maneira de aproximação e de produção dos dados que apresentamos neste texto. A conversa transitará como uma forma de forjar compreensões e problematizá-las. Conversar, portanto, se configura como "uma forma relativamente simples de relação humana" (Elias 25).

Nessa direção, tomamos a conversa como uma forma de constituição de indivíduos de uma determinada sociedade, cujas maleáveis estruturas operam "a modelagem geral e, portanto, a formação individual de cada pessoa depende da evolução histórica do padrão social, da estrutura das relações humanas" (Elias 24). A partir do estudo desenvolvido acerca do processo civilizador, Elias descreve o funcionamento da conversa da seguinte forma:

Um parceiro fala, o interlocutor retruca. O primeiro responde e o segundo volta a replicar. Se considerarmos não apenas as observações e contra-observações isoladas, mas o rumo tomado pela conversa como um todo, a sequência de ideias entremeadas, carreando umas às outras numa interdependência contínua, estaremos lidando com um fenômeno que não pode ser satisfatoriamente representado nem pelo modelo físico da ação e reação das bolas nem pelo modelo fisiológico da relação entre estímulo e reação. (Elias 25).

Ao descrever esse tipo de relação usando a metáfora de bolas de bilhar, Elias (25) pontua que as relações entre as pessoas são assim imaginadas, pois comumente se chocam e rolam em direções distintas. Em contrapartida, o autor nos convida a repensar esse argumento discutindo que "partir de uma estrutura tecida na forma de rede - [...] expressa a condição relacional de seus componentes" (Setton 204). Essa estrutura foi nomeada "imagem/fenômeno reticular" e é vista como um processo que tem como característica especial o fato que,

Cad. Trad., Florianópolis, v. 41, $\mathrm{n}^{0}$ esp. 2, p. 273-302, ago/dez, 2021. 281 
[...] no decorrer dele, cada um dos interlocutores forma ideias que não existiam antes ou leva adiante ideias que já estavam presentes. Mas a direção e a ordem seguidas por essa formação e transformação das ideias não são explicáveis unicamente pela estrutura de um ou outro parceiro, e sim pela relação entre os dois. E é justamente esse fato de as pessoas mudarem em relação umas às outras e através de sua relação mútua, de se estarem continuamente moldando e remoldando em relação umas às outras, que caracteriza o fenômeno reticular em geral. (Elias 25).

A partir da descrição da conversa como elemento que atravessa as relações humanas, podemos prosseguir com as problematizações sobre como TILSP são subjetivados e se subjetivam por uma série de técnicas. Reforçamos que, ao nos utilizar da conversa como forma de produção de dados, não as tomamos "como uma unidade distinta que existisse com uma ordem própria” (Elias 25). Ao contrário disso, "a experiência de si, também é algo histórica e culturalmente contingente, na medida em que sua produção adota formas 'singulares"” (Larrosa 41). Desse modo,

a pessoa individual não é um começo e suas relações com as outras não têm origens primevas. Assim como, numa conversa contínua, as perguntas de um evocam as respostas do outro e vice-versa, e assim como determinada parte da conversa não provém apenas de um ou do outro, mas da relação entre os dois. (Elias 30).

A subjetivação pela qual nos constituímos (e somos constituídos) como TILSP, em suma, não se configura como um processo dissociado de uma sociedade e de um período (temporal) específicos. A relação desses sujeitos TILSP com a formação é atravessada por experiências, que emergem de uma matriz de funcionamento,

Cad. Trad., Florianópolis, v. 41, $\mathrm{n}^{0}$ esp. 2, p. 273-302, ago/dez, 2021. 282 
modeladas e endereçadas por meio de um arsenal de técnicas traduzidas em verdades e validadas por normativas.

Se analisássemos a formação de TILSP, a partir desse cenário, que nutre seu funcionamento a partir de uma "padronização muito difundida da autoimagem" (Elias 27) ou por meio de "como universais antropológicos, caracterizam a pessoa humana, nos dizem o que é o sujeito são ou plenamente desenvolvido" (Larrosa 42), correríamos o risco de caminhar pela via socrático-platônica da linguagem como única produtora da verdade e, desse modo, adentraríamos numa perspectiva de julgamento em que as formações de TILSP

\begin{abstract}
[...] foram obrigadas a adotar um grau elevadíssimo de refreamento, controle afetivo, renúncia e transformação dos instintos, e que estão acostumadas a relegar grande número de funções, expressões instintivas e desejos a enclaves privativos de sigilo, afastados do olhar do "mundo externo". (Elias 27).
\end{abstract}

Nesse sentido, ao se aproximar das teorizações foucaultianas, Larrosa (43) propõe uma inversão de perspectiva que simultaneamente faz um exercício de "interrogar os universais antropológicos em sua constituição histórica" e, continua o autor, "a fim de problematizar as ideias com respeito à autoconsciência, à autonomia ou à autodeterminação, analisando as condições históricas de sua formação na imanência de determinados campos de conhecimento" (Larrosa 43). Outro movimento necessário seria perceber os mecanismos de produção das experiências de sujeitos (TILSP) como desdobramento de práticas concretas "nas quais se estabelecem, se regulam e se modificam as relações do sujeito consigo mesmo e nas quais se constitui a experiência de si" (Larrosa 44). Portanto, a formação-experiência como despossibilidade para TILSP, além de se situar nesse fluxo de produção de subjetividades, pode ser um modo de revisitar nossa constituição como não natural.

A formação de sujeitos TILSP pode ser modulada em (im)possibilidades nas quais emergem tipos/formas de vidas específicas

Cad. Trad., Florianópolis, v. 41, $\mathrm{n}^{0}$ esp. 2, p. 273-302, ago/dez, 2021. 283 
de um determinado tempo que, dentro e através da relação com o outro, (i) "assume a forma que lhe é específica" (Elias 29) e/ou torna-se essa forma; (ii) "tanto o que é ser pessoa em geral como o que para cada uma é ser ela mesma em particular" (Larrosa 45).

Para que as conversas acontecessem no contexto de isolamento físico dada a pandemia mundial que vivemos, neste tempo, a estrutura cronológica (oportuna e intensiva) desenvolvida contemplou duas etapas. No primeiro momento, a conversa e os caminhos subsequentes foram iniciados, em abril de 2020, na Mesa Redonda on-line, intitulada "E por falar em formação: notas de um começo", composta por três docentes da UFES. ${ }^{5}$ A partir desse evento, no segundo momento, abrimos caminhos para aproximações com colegas TILSP em todas as regiões brasileiras por meio de um formulário criado especificamente com o intuito de agrupar colegas de diferentes contextos (estado/regiões) do Brasil.

No mesmo dia do evento supracitado, anunciamos e colocamos em circulação um formulário redigido com base nas diretrizes do Termo de Consentimento Livre e Esclarecido (TCLE). Construímos esse formulário utilizando a plataforma Google Forms, sendo composto pelo Termo de Consentimento Livre e Esclarecido (TCLE) e por seis perguntas (cinco obrigatórias e uma opcional): (1) E-mail, (2) Nome, (3) Nome Social (não obrigatória), (4) Você é: (a) surdo ou (b) ouvinte?, (5) Qual período você teria mais disponibilidade para participar do nosso encontro virtual? e; (6) Estado em que reside.

Sem objetivar uma análise quantitativa, o formulário teve 328 respostas advindas dos estados brasileiros listados em ordem alfabética: 23 do Acre (AC), 5 do Amazonas (AM), 19 da Bahia (BA), 6 do Ceará (CE), 7 do Distrito Federal (DF), 91 do Espírito Santo (ES), 8 de Goiás, (GO), 2 do Maranhão (MA), 7 do Mato Grosso

5 Com os seguintes temas: (1) "Pedagogia Menor como Política Linguística" (professora Dra. Junia Mattos Zaidan), (2) Formação: "Experiências de si e memórias traduzidas" (professora Dra. Lucyenne Matos da Costa Vieira-Machado) e (3) "Conversa com vetor para constituição do habitus social" (professor Dr. Reginaldo Célio Sobrinho).

Cad. Trad., Florianópolis, v. 41, $\mathbf{n}^{0}$ esp. 2, p. 273-302, ago/dez, 2021. 284 
(MT), 25 do Mato Grosso do Sul (MS), 31 de Minas Gerais, 6 do Pará (PA), 3 da Paraíba (PB), 8 do Paraná (PR), 11 do Pernambuco (PE), 1 do Piauí (PI), 15 do Rio de Janeiro (RJ), 6 do Rio Grande do Norte (RN), 9 do Rio Grande do Sul (RS), 4 de Rondônia (RO), 1 de Roraima (RR), 4 de Santa Catarina (SC), 30 de São Paulo (SP), 5 do Sergipe (SE) e 1 do Tocantins (TO).

A partir do grande número de interessados em participar das conversas, dividimos os grupos em salas criadas na ferramenta Google Classroom (Google Sala de Aula). Em todas as salas (no total de 14), havia colegas das cinco regiões brasileiras; no total foram 122 participantes. As conversas foram produzidas, gravadas e transcritas em língua portuguesa e, nas salas onde tinham surdos, contamos com a presença de duas colegas e parceiras que realizaram a interpretação simultânea de/para Libras. Os sujeitos surdos participantes foram distribuídos nas salas que contemplavam os horários disponíveis para as intérpretes envolvidas na pesquisa. Não foram feitas salas só de surdos.

Cada encontro com colegas contou com 5 perguntas/tópicos que serviram como disparadores e partiram do uso das dimensões constitutivas do sujeito baseados no texto "Tecnologias do Eu" de Larrosa (1994), a saber: "olhar-se, expressar-se, narrar-se, julgarse e dominar-se".

\section{Linhas de fuga ou sobre a fugacidade da bolha de sabão: a formação dos TILSP como obra de arte}

A fim de responder aos objetivos supracitados de analisar e problematizar como, no processo formativo, vêm sendo constituídas as tecnologias de modulação nas condutas correlatas a uma racionalidade política moderna dos TILSP, descreveremos aqui, a partir das conversas, como as condutas deles vão sendo moduladas não apenas como sujeição, mas também como rotas de fuga.

Cad. Trad., Florianópolis, v. 41, $\mathbf{n}^{0}$ esp. 2, p. 273-302, ago/dez, 2021. 285 
As tecnologias da subjetivação são, pois, as maquinações, as operações pelas quais somos reunidos, em uma montagem, com instrumentos intelectuais e práticos, componentes, entidades e aparatos particulares, produzindo certas formas de ser-humano, territorializando, estratificando, fixando, organizando e tornando duráveis as relações particulares que os humanos podem honestamente estabelecer consigo mesmos. (Deleuze 176).

Analisamos os discursos produzidos por meio das conversas através da matriz de experiência como vetor. Temos como primeiro e segundo domínios da matriz, o saber e o poder. Porém optamos por discutir, neste texto, o terceiro domínio da matriz de experiência, a ética (subjetivação). Vale a pena trazer um trecho de uma cena entre a Alice e a Largarta para compor um fluxo de pensamento.

\begin{abstract}
"Quem é você?", disse a Lagarta.
Não era um começo de conversa muito estimulante. Alice respondeu um pouco tímida: "Eu... eu... no momento não sei, minha senhora... pelo menos sei quem eu era quando me levantei hoje de manhã, mas acho que devo ter mudado várias vezes desde então".

"O que você quer dizer?", disse a Lagarta ríspida. "Explique-se!"

"Acho que infelizmente não posso me explicar, minha senhora”, disse Alice, "porque já não sou eu, entende?"

"Não entendo", disse a Lagarta.

"Receio não poder me expressar mais claramente", respondeu Alice muito polida, "pois, para começo de conversa, não entendo a mim mesma. Ter muitos tamanhos num mesmo dia é muito confuso." (Carroll 61).
\end{abstract}

No trecho supracitado, ao ser indagada pela Lagarta sobre quem ela era, Alice se vê numa situação um tanto complexa: como res- 
ponder quem era ela se, num único dia, havia sido tantas, pois crescera e diminuíra tantas vezes. Trazendo a discussão para este texto: como esses processos de singularidades possíveis podem contribuir para pensarmos a formação do TILSP no nosso tempo? E mais, como forjar linhas de fuga que contribuam para outras formas de posicionamento dos TILSP diante das políticas de verdade moduladas na sociedade de controle na qual vivemos?

Ao descrever a forma como Carroll lida com seu modo de escrita, Deleuze (2011) observa que "tudo em Lewis Carroll começa com um combate horrível” (Deleuze 34). Para o filósofo, os combates trazidos na literatura de Carroll se dão nas profundezas onde existe uma mistura dos corpos que se nutrem através de um canibalismo. "Nas profundezas tudo é horrível, tudo é não-senso" (Deleuze 34).

O próprio título da obra seria: As aventuras subterrâneas de Alice, e interessa-nos, neste trabalho, estabelecer com a personagem de Carroll as possibilidades de emergência para a superfície. Criar superfícies mesmo estando em movimentos de afundamento. Desse modo, criar linhas de constituição de uma formação que vê no afundamento a potência de criação para além dos limites impostos por ela.

Pensar a própria noção de formação de (nós) TILSP como foco de experiência se configurou num exaustivo exercício de revisitas a partir de exercícios de deslocamentos provocados por eles. Para pensar as formas de subjetivação produzidas, dialogamos aqui com Negri e Hardt (2014). Esta obra trouxe, dentre outras coisas, uma rota que possibilitou problematizar a formação de TILSP dentro de uma ordem neoliberal, que tanto na sua ascensão como na crise, "mudaram os termos da vida econômica e política, mas também operaram uma transformação social e antropológica, fabricando novas figuras de subjetividade" (Negri and Hardt 21).

Os movimentos investigados pelos autores lançam quatro "formas dominantes de subjetividades produzidas no contexto da crise social e política corrente [...] os quais estão empobrecidos, com seus poderes relativos à ação social, mascarados ou mistificados" (Negri and Hardt 15-6). 
Em síntese, trata-se das figuras subjetivas constituintes do terreno social pelo qual devem agir em movimentos de resistência. De acordo com os filósofos, as quatro figuras se resumem da seguinte forma:

\begin{abstract}
A hegemonia das finanças e dos bancos produziram o endividado. O controle das informações e das redes de comunicação criaram o mediatizado. $\mathrm{O}$ regime de segurança e o estado generalizado de exceção construíram a figura oprimida pelo medo e sequiosa de proteção: o securitizado. E a corrupção da democracia forjou uma figura estranha despolitizada: o representado. (Negri and Hardt 21).
\end{abstract}

A aproximação que fazemos se deve, sobretudo, a possibilidades de criar ações que excedem os limites sobre as quais emergem as figuras subjetivas (e nós TILSP) ou, como destacado na obra, "os movimentos de revolta e rebelião nos proporcionam os meios não só para recusar os regimes repressivos [...] mas também para converter essas subjetividades em figuras de poder" (Negri and Hardt 15-6). A formação como experimentação, ou formação-experiência é passível de problematização, pois

formar para não permanecer órfão de tradição; educar para não aceitar a tradição como um valor absoluto; experimentar para não permanecer na atitude negativa da crítica que isenta o indivíduo de criar um referencial quando nenhum referencial externo faz mais sentido. Essa sequência pode ser interpretada como um ideal pedagógico, na medida em que incorpora tanto a pertença a uma tradição, quanto a sua crítica, bem como a tarefa de recriação do sentido num mundo em crise. Embora possa parecer forçado demais, é exatamente disso que se trata quando a crise se torna modo próprio de ser, do homem e do mundo. (Weber 164).

Cad. Trad., Florianópolis, v. 41, $\mathrm{n}^{0}$ esp. 2, p. 273-302, ago/dez, 2021. 288 
Além da possibilidade que descrevemos acima, a formação de (nós) TILSP, atravessada pelos acontecimentos com os quais emergiu e tem se reinventado, quando circunscrita nas figuras subjetivas, são movimentos que podem não apenas agir, recusar e resistir às subjetividades dominantes do nosso tempo, "mas também de invertê-las"” (Negri and Hardt 21). Desse modo, "como nos ensinou Hannah Arendt, é justamente nos momentos de crise que podemos intervir mais efetivamente no sentido de mudar o rumo das coisas, de tentar mudar o mundo" (Veiga-Neto s/p).

As nomeações dadas para modos específicos de subjetividade não são categorias estanques, mas coexistentes entre si. Argumentamos que, sendo (nós) TILSP uma invenção do nosso tempo, somos capturados pelo funcionamento da matriz de pensamento vigente e, desse modo, produzimos e somos produzidos na correlação de quatro subjetividades: (i) TILSP Endividado; (ii) TILSP Mediatizado; (iii) TILSP Securitizado; e (iv) TILSP Representado. Para este texto, seguimos com a discussão do TILSP Securitizado.

\subsection{TILSP Securitizado: sobre a segurança e a insegurança da estrutura}

Nessa figura subjetiva, sintetizamos que (nós) TILSP, a partir da necessidade de formação constante, fortalecida por dispositivos midiáticos e legitimadas por múltiplos outros dispositivos (leis, instituições etc.), caminham para um posicionamento caracterizado pelo medo e pela constante necessidade de buscar meios para a garantia de segurança. Essa figura subjetiva é descrita como coexistente aos contextos de instabilidade política pelos quais as nações contemporâneas estão passando, e que, de certo modo, tais contextos também se evidenciam como estratégia para promover esse cenário de instabilidade.

Mesmo sendo capturados pela representação, pela mediatização e pelo endividamento, a vigilância é um elemento refinado desde as sociedades disciplinares até as sociedades de controle. Essa reinvenção não significa substituição das técnicas de uma sociedade por

Cad. Trad., Florianópolis, v. 41, $\mathrm{n}^{0}$ esp. 2, p. 273-302, ago/dez, 2021. 289 
outra, mas implica uma nova forma de governamento dos sujeitos (TILSP) constituída simultaneamente pela reinvenção e pelo acoplamento das caraterísticas antecedentes. O TILSP Securitizado, nesse sentido "[...] é uma criatura que vive [e] prospera num estado de exceção, no qual o funcionamento normal do primado da lei e dos hábitos das leis e vínculos convencionais de associação foram suspensas por um poder abrangente" (Negri and Hardt 34).

Conversando aqui conosco, o trabalho de Santos (2006) nos apresenta posicionamentos analíticos muito pertinentes quando, a partir da análise de excertos do corpus de sua pesquisa, que são narrativas de TILSP entrevistados, a autora argumenta "[...] que a ausência do trabalho de apoio de outro colega ILS [intérprete de línguas de sinais] com mais experiência para auxiliar a interpretação, a falta de formação, entre outros fatores, têm contribuído para dificultar as primeiras atuações dos intérpretes em seus trabalhos (Santos 83). Ao desenvolver os argumentos envolvidos na trama, os profissionais justificavam sua inserção na atividade como única opção para surdos em contextos conflituosos, haja vista a escassez de profissionais naquela época.

Entendendo a dissertação de Santos, defendida em 2006, quando dispositivos legais ainda institucionalizavam a formação para TILSP no Brasil, faz muito sentido falar da falta de profissionais ou da falta de formação. Porém, quando vimos, em 2021, a reprodução de alocuções que repetem a "falta de formação", percebemos como essa regularidade discursiva se constitui e como se prolifera como verdade.

Olhando para os quinze anos que separam a pesquisa de Santos para as nossas análises recentes sobre a questão da formação de TILSP, percebemos que a produção da verdade da necessidade de formação lança uma justificativa para a necessidade de ofertá-la. Consideramos pertinentes os apontamentos que compõem o trabalho de Santos (2006) ao mesmo tempo que chamamos atenção para tencionar algumas afirmativas como:

Cad. Trad., Florianópolis, v. 41, $\mathrm{n}^{0}$ esp. 2, p. 273-302, ago/dez, 2021. 290 
Se aceitarmos essas afirmações, do tipo "se não tem um profissional habilitado, vai aquele que, mesmo sem habilidades, mas que conhece a LS pode atuar", a má qualidade de interpretação, a falta de formação dos ILS se tornará uma prática normalizadora, ou seja, sabemos a precariedade dessa situação e não criamos estratégias de mudanças, deixando da maneira como está, tornando um discurso como se a maioria dos ILS tem uma formação precária e isso é "normal". (Santos 84).

Junto ao argumento que Santos (2006) propõe acerca da normalização de algumas práticas de formação, também podemos problematizar essa questão (da normatização) como prática associada à falta de formação de TILSP. O enunciado registrado no trabalho de Silva (2006) é um dos exemplos (ao lado de Quadros, 2004; Rosa, 2005; dentre outros) que compõem uma regularidade discursiva, que, muito embora contribuíram e contribuem para o avanço das pesquisas e para o fortalecimento da categoria, são vetores constituintes de uma política de verdade "da falta de formação" perpetuada até os dias atuais. Além do fortalecimento como desdobramento, chamamos atenção para o efeito de raridade pelo qual essa verdade se reproduziu.

(TILSP-SC) Eu trabalho na tradução de português-inglês há cinco anos e me formei para atuar. Eu aliei o que aprendi na formação universitária, que não foi tudo, mas adquiri coisas conforme fui trabalhando, sabe? Pra mim a formação pra TILSP seria tipo: não apenas aprender a língua, mas em função do trabalho a ser realizado como profissional. $\mathrm{Na}$ minha visão, a formação institucional me faz sentir mais segura (com cursos diversos) e posteriormente acrescida das experiências de trabalho.

(TILSP-BA) [...] a realidade dos alunos é não ter o bacharelado no Estado. A maioria mora em cidades distantes da 
capital e perguntam-se constantemente: "Só posso ser TILS reconhecido se tiver um bacharelado? Não há outro tipo de formação que me capacite para isso? Não há outro tipo de formação que me dê autonomia para que eu seja um bom profissional?

Nas conversas com TILSP, a formação foi expressa partindo do denominador comum da ausência. Mesmo entre TILSP com formação no bacharelado (ainda que em menor número) ou até profissionais com certificação em nível de extensão, é possível identificar similaridades apontadas com as pesquisas que antecedem a criação do curso superior da área.

(TILSP-RS) Eu sou uma intérprete que precisa muito de feedback pra me sentir mais segura, por ser muita insegura, então tem a ver um pouco com essa falta de formação, [...] ainda me considero despreparada com uma formação insuficiente, então a opinião de terceiros me influencia muito. Tenho medo das críticas dos profissionais da área, porque já passei por uma experiência negativa na qual eu não recebi críticas construtivas, infelizmente, e isso acaba atrapalhando na minha formação, na minha segurança como intérprete também, mas estou buscando.

(TILSP-MT) Eu fiquei pensando nessa questão da autoestima, porque eu já trabalhei sobre isso também. Sobre a autoestima do intérprete, eu vejo muito essa questão da insegurança e ela vem realmente, e é algo que eu tenho sentido. É uma insegurança, porque começamos em meios informais de ensino, e quando começamos a atuar, nos questionamos: "será que estou pronta?" Porque, às vezes, não temos um diploma em Letras-Libras focado na interpretação.

(TILSP-DF) Não me sentia segura pra me considerar e bater no peito e dizer "uau, eu sou intérprete", então, pra mim, foi um processo bem lento, porque demorei uns dois-três

Cad. Trad., Florianópolis, v. 41, $\mathrm{n}^{0}$ esp. 2, p. 273-302, ago/dez, 2021. 292 
anos. Mesmo trabalhando na função, eu tinha um receio absurdo, um medo, aquela tensão, aquele medo do olhar do outro, dos outros intérpretes, dos comentários do que pode ou o que não pode.

O saber, o poder e o si são a tripla raiz de uma problematização do pensamento. Sobre essas três questões, (nós) TILSP Securitizados nos baseamos na ideia e no desejo de existência condicionada a um terreno no qual não haveria incertezas, assim como em contratos, analisados por Zuboff (42):

\begin{abstract}
a certeza exige "racionalidade ilimitada" derivada de "competência cognitiva irrestrita", que, por sua vez, deriva de adaptações "completamente descritas" a eventos contingentes "publicamente observáveis" [...] Williamson observa que essas condições são inerentes a "um mundo de planejamento", e não ao "mundo da governança", no qual, "outras coisas sendo iguais [...], as relações que se caracterizem pela confiança pessoal sobreviverão a um maior estresse e mostrarão maior adaptabilidade”. (Zuboff 42).
\end{abstract}

No desenvolvimento dos argumentos de Zuboff (2019), a seguridade prometida por contratos tem como efeito o aumento do domínio sobre os indivíduos. Corroborando Hanna Arendt, Zuboff (2019) destaca que

[...] a falibilidade humana na execução de contratos é o preço da liberdade. A impossibilidade do controle perfeito dentro de uma comunidade de iguais é a consequência da "pluralidade e realidade [...] a alegria de habitar junto com os outros um mundo cuja realidade é garantida para cada um pela presença de todos". Arendt insiste que "a força de promessa ou contrato mútuo" é a única alternativa "a um domínio que depende da dominação de si mesmo e do governo sobre os outros; isso corresponde exatamente à ex-

Cad. Trad., Florianópolis, v. 41, $\mathrm{n}^{0}$ esp. 2, p. 273-302, ago/dez, 2021. 293 
istência de liberdade que foi dada sob a condição de não soberania. (Zuboff 43).

Com esses direcionamentos, retomo outros trechos de conversas com TILSP para evidenciar algumas formas com que a securitização está associada. Vejamos:

(TILSP-MG) Então, assim, hoje eu confesso que eu não passei por nenhuma graduação de letras libras, nem de letras e [...] confesso que eu já li tanta coisa que eu poderia me dar um diploma, né? Mas é uma questão que me incomoda muito por conta de, às vezes, você abrir mão de uma formação vertical para ter informação na horizontal. Só por conta de um lugar de fala para você se legitimar. Olha, eu estou falando como tradutor intérprete. Estou falando como tradutor de libras, porque eu tenho esse certificado, né?

(TILSP-AC) Eu me chamo H., do Acre, sou intérprete há mais ou menos dois anos [...] Eu também comecei no religioso. E aí fui fazendo alguns cursos, fiz a formação de curso de extensão [...] ainda é uma luta constante, a gente tá sempre buscando aprendizado. A gente tá sempre buscando entender mais sobre a formação, né? Aqui a gente, aqui no Acre de certa forma, ainda tá começando a ter com mais frequência, mas [...] um ano atrás, mais ou menos, quando eu comecei, não tinha, dificilmente você ouvia falar, né? E aí hoje a gente já trabalha melhor e a gente tem Associação aqui também que nos auxilia bastante, né? E assim que estão com os professores, né? Ainda tenho muito contato... são, assim, pessoas que me auxiliam bastante, eu acho que é muito importante a gente, quando a gente começa, importante ter [com quem] compartilhar e os professores dos cursos que eu frequente i, não só isso, mas os surdos também, eles sempre estão ali compartilhando. Inclusive eu. 
(TILSP-ES) Entendo que a formação vai além da questão formal de se ter certificado. Lógico que para a questão acadêmica, laborativa, situações comuns, é fundamental a certificação. Contudo, assim como na graduação, você não sai totalmente apto, uma formação formal não significa ser formador de TILS. A vivência com o ser surdo, e entender, compreender sua visão de mundo é muito mais "formativo". Pois, interpretar e traduzir é fazer a comunicação. Tornar comum.

(TILSP-SC) Quem então pode ser TILS? É obrigatório ter o Letras Libras bacharelado? Não é? Tem que ter curso técnico ou não tem? [Com] quantas horas de certificado me torno um intérprete? Isso é bem complicado. Porque o Letras Libras é bem recente. Então os profissionais que atuavam antes dos bacharelados não são tão intérpretes quanto os que se formaram agora? Não temos, de forma clara, específica, o que te exige, quais os documentos ou quais níveis de formação são exigidos para atuarmos como intérpretes em legislação descrito dessa forma. Então, uma discussão muito bacana. Acredito que não seja um diploma apenas que vai te formar intérprete, acho que todas as experiências que você tem, a bagagem empírica que você adquiriu.

(TILSP-SP) E para finalizar, eu sei que essa pergunta "quando que eu me tornei intérprete?" incomoda, no bom sentido, e temos que nos localizar e nos entender em algum momento, e isso também é uma boa conversa com a própria comunidade surda, com sujeitos surdos, mas é um olhar complexo, é um acontecimento que não vem de um lugar só, não vem de uma mão única, não é uníssono, ele é diverso e isso não tem nenhum problema em ser assim, é o seu processo, respeite a sua história e faça as pazes com a sua história. Eu já vivi muitas inquietações, mas a gente entender que essa história, essa diversidade também nos constitui e também é fruto do que somos hoje, isso é muito rico e é a nossa história, diferente da medicina que talvez veio de história mais padronizada, e o nosso não, e estamos aí. 
Nos excertos a seguir, o posicionamento de TILSP atrela a segurança condicionada à formação obtida através do bacharelado. Conforme argumentamos anteriormente, o curso é fruto de um movimento político que muito contribuiu para a profissionalização de TILSP, inclusive como um ideal desejado e colocado em muitas conversas. O que queremos pontuar, porém, é o fato de ela ser considerada uma "única" ou "A Melhor" forma possível de ser um TILSP produz subjetividades TILSP securitizadas.

(TILSP-PE) Eu fico pensando que as características que temos que ter são eternas, porque sempre vai ter uma coisa nova que vamos precisar ter, um novo para se adquirir, algo para se conquistar e isso me deixa fascinada. E eu só fico triste, porque aqui, na minha região, não temos oportunidade em questão de formação, e tudo que buscamos vem de vocês aí de fora, e é em vocês que eu vou me agarrar para ver se consigo chegar lá fora, não sei onde, mas eu quero chegar lá!

(TILSP-SE) Temos que buscar fora, porque aqui não tem nada ofertando de formações, e as formações que existem temos que buscar em outras [...] Buscar formação fora, cursos EAD fora, minha formação agora vai ser EAD, por videoaulas através de webinário e isso vem me fortalecendo e eu tinha essa frustração comigo por não ter uma formação, um conhecimento mais amplo, e eu estava sendo uma intérprete frustrada pela questão da classe.

(TILSP-PE) Então, realmente a formação para mim vai além de um simples papel, para mim o que importa, de fato, é a prática, mas não só importa para a gente porque precisamos de um conhecimento mais profundo disso, é uma questão linguística [de] morfema, [de] semântica, é sobre ter um conhecimento a mais do que estamos praticando ali a fundo, não é sobre saber o sinal, mas sim o que constitui o sinal, qual movimento devo fazer, é se aprofundar mais 
sobre o sinal. Eu também agora estou em uma oficina de música do lado do Ceará, [...] eu busquei também a distância, a professora ensina uma cultura que muitos surdos não tinham e que muitos não gostam de música e respeitamos é claro, mas também tem muitos surdos que gostam de música e temos que ampliar isso, pois não é porque um gosta e o outro não que vamos aprender aquilo ali, é sempre estar buscando mais e se aprofundando. E para mim o que eu entendo como formação é uma prática a nível tradutório e interpretativo. Uma formação a qual [temos] que estar praticando a toda hora, se analisando, se autoavaliando, porque o que importa é o contato com a comunidade surda.

(TILSP-ES) No dia a dia, porém, a gente procura fazer o melhor possível, a gente procura estar trabalhando, fazendo aquilo que [nos] propomos, né? a fazer, né? Honrar com a nossa profissão, né? Para que possamos ter uma valorização dentro da escola, porque eu costumo dizer que um intérprete, ele se forma, ele pode fazer vários cursos.

As contribuições trazidas por Hanna Arendt, em seu livro A condição Humana, são fundamentais para problematizar nosso modo de ser (nós) TILSP Securitizados. Conforme salienta a autora,

a última etapa da sociedade do trabalho, a sociedade dos empregados, exige dos seus membros um completo funcionamento automático, como se a vida individual tivesse sido realmente mergulhada no ciclo vital da espécie e a única decisão ativa ainda necessária do indivíduo fosse largar tudo, por assim dizer, abandonar sua individualidade, a dor individualmente sentida e o problema de viver, e concordar com um comportamento funcional atordoado e "tranquilo". O problema com as teorias modernas do behaviorismo não é que elas estejam erradas, mas que elas possam se tornar verdadeiras, que elas sejam a melhor conceitualização possível de certas tendências óbvias na sociedade moderna. É 
bem concebível que a era moderna - que começou com um surto promissor e sem precedentes de atividade humana - possa acabar na mais letal e estéril passividade que a história já conheceu. (Arendt 322).

Nesse sentido, a confiança estabelecida por (nós) TILSP Securitizados se pauta na ideia de uma formação (no caso contemporâneo, o bacharelado) racionalizada como facilitadora e garantidora do caminho para atuação cotidiana. Podemos perceber tanto nos movimentos de sujeição como nas linhas de fugas. Quando o TILSP se questiona se não ter o bacharelado, por exemplo, não o torna menos TILSP, e assim busca outros caminhos, a experimentação, mais uma vez, pode ser evocada como modo de intensificar os acontecimentos que transcorrem em nossos cotidianos. A formação-experiência nos convida a "aprender a pensar de outra forma - para enfim, talvez bem mais tarde, alcançar ainda mais: 'sentir de outra forma" " (Nietszche 75).

Desse modo, essa experimentação não anula ou se opõe ao desejo de uma profissionalização que se dá por vias acadêmicas ou outras quaisquer, mas dentro dos limites estabelecidos como impossíveis, o que forja, assim, possibilidades ou, como em Alice, despossibilidades.

\section{Considerações outras: liberte-se, pois, enfim, a bolha se rompe}

Nesta aventura de uma escrita-experiência, decompomos o conceito de formação a partir de sua despossibilidade como a estrutura de uma bolha de sabão. Nossa caminhada, até aqui, nos possibilitou subverter alguns conceitos caros e fundamentais a partir de problematizações outras saindo do par técnica-ciência e teoria-prática, mas abusando do par experiência-sentido (Larrosa).

Escolhemos ser travessos quando decidimos cunhar o termo formação-experiência para problematizar a ideia dura de forma-

Cad. Trad., Florianópolis, v. 41, $\mathrm{n}^{0}$ esp. 2, p. 273-302, ago/dez, 2021. 298 
ção que sujeita, pois acreditamos que toda subjetivação sujeitada é capaz de revoltar-se, principalmente, quando conhece os mecanismos de sujeição. Segundo Negri e Hardt, todas as quatro figuras dominadas (subjetividades endividadas, securitizadas, representadas e mediatizadas) também possuem a capacidade de tornar-se figuras de poder. "Essa inversão é o resultado não de um processo dialético, mas de um evento, de um kairós subjetivo que rompe as relações de dominação e subverte os processos que reproduzem as figuras de subjugação" (Negri and Hardt 49).

Por isso, liberte-se! Revolte-se! Recuse! Rompa a estrutura! "Todavia, você só é capaz realmente de recusar e fugir quando reconhece seu poder" (Negri and Hardt 60). Use as linhas de fuga para construir outras (des)possibilidades.

Reiteramos aqui que não somos contra as formações maiores, moduladas e institucionalizadas, pois elas são resultadas das lutas da categoria, são conquistas muito importantes e devem se tornar comuns e estar acessíveis a todos. Afinal,

o conhecimento é um bem comum por excelência e a educação depende do acesso ao conhecimento, às ideias e à informação. Criar planos de acesso livre a esses bens é evidentemente um pré-requisito para qualquer ideia de educação como instituição do comum. (Negri and Hardt 104).

E justamente pelo fato de reconhecermos que vivemos em um estado de exceção em que isolados despotencializamos o sujeito e em que o fato de a educação não ser um bem comum é um projeto desse Estado, entendemos que a formação-experiência, como atitude, torna-se a lacuna entre ser ou não ser TILSP e ela só pode ser produzida no espaço do comum e se encontra no Ser em qualquer espaço. Sabendo que as instituições chegam com uma velocidade maior nos diferentes locais principalmente de forma mediatizada, entendemos assim que a atitude é do sujeito ao se produzir TILSP não importa em qual espaço formativo. 
Por isso não podemos negar o autodidatismo e as buscas por diferentes vias formativas afinal a formação não é apenas uma questão de conhecimento, pois ao estudar, obviamente, conhecimentos serão adquiridos, contudo, a inteligência também é estimulada e, portanto, o poder de exercer o pensamento também o é (Negri and Hardt 2014). "Nesse sentido, em seu nível mais básico, a educação é sempre um autodidatismo" (Negri and Hardt 104).

Claramente, o autodidatismo não significa a destruição da formação direcionada por instituições. Não significa a ausência do professor, significa a possibilidade do estudo e, para isso, ambientes propícios devem ser criados, o que, no modelo atual de educação, é bastante raro. "O autodidatismo deve ser organizado como exemplo [...] de acesso livre ao comum, incluindo informações, conhecimentos, ferramentas de estudo etc. livre de obstáculos financeiros e também de obstáculos provenientes do dogmatismo e da censura" (Negri and Hardt 105).

Nas vozes ecoadas nas conversas com os diferentes TILSPs dos diferentes espaços/lugares, mesmo sendo do mesmo país, mostram em vários momentos que, embora em meio à busca de segurança, o autodidatismo não se configura como uma atitude isolada, mas comum. "O tipo de autodidatismo que estamos discutindo aqui é [...] afetivo, e também social e científico [...] e não é individual. Só podemos estudar em relação e em interação com os outros, quer eles estejam fisicamente presentes ou não" (Negri and Hardt 105).

A formação-experiência, então, torna-se um caminhar em direção do encontro das diferentes singularidades, produzindo, assim, sujeitos-potências capazes de rebelar-se e produzirem-se em figuras de poder a partir de subjetividades outras não nomeadas.

Cad. Trad., Florianópolis, v. 41, $\mathrm{n}^{0}$ esp. 2, p. 273-302, ago/dez, 2021. 300 


\section{Referências}

ALICE Através do Espelho. Direção James Bobin. Produção: Joe Roth, Suzanne Todd, Jenifer Todd e Tim Burton. Walt Disney (1h50min). Estados Unidos da América. 2016.

Arendt, Hanna. A condição humana. Tradução: Roberto Raposo. 12 ed. rev Rio de Janeiro: Forense Universitária, 2014.

Berman, Antoine. A prova do Estrangeiro. Tradução de Maria Emília Pereira Chanut. Bauru, SP: EDUSC, 2002.

Carroll, Lewis. Alice no país das maravilhas. Tradução, introdução e notas de Isabel de Lorenzo. Tradução dos poemas de Nelson Ascher. Apresentação de Francisco Achcar. 2. ed. São Paulo: Editora, 2000.

Deleuze, Gilles; Guarttari, Félix e Parnet, Claire. Diálogos. Tradução de José Gabriel Cunha. Lisboa: Relógio D’agua, 2004.

Deleuze, Gilles e Guattari, Félix. Foucault. Tradução de Cláudia Santana Martins. Revisão da Tradução de Renato Ribeiro. São Paulo: Brasiliense, 2005.

Deleuze, Gilles e Guattari, Félix. Crítica e Clínica. Tradução de Pál Pelbart. 2. ed. São Paulo: Editora 34, 2011.

Elias, Norbert. A sociedade dos indivíduos. Tradução de Vera Ribeiro. Rio de Janeiro: Jorge Zahar, 1994.

Fischer, Rosa Maria Bueno e Veiga-Neto, Alfredo. "Foucault: um diálogo". Educação e Realidade, Porto Alegre, 29.1, (2004): 7-25.

Negri, A e Hardt, M. Declaração - isto não é um manifesto. Tradução de Carlos Szlak. São Paulo: n-1 edições, 2014. 
Larrosa, Jorge. "Tecnologias do Eu e Educação". O sujeito da Educação: estudos foucaultianos, organizado por T. T. Silva. Petrópolis, Rio de Janeiro: Vozes, 1994, pp. 35-86.

Larrosa, Jorge. "Experiência e paixão". Linguagem e educação depois de Babel, organizado por Jorge Larrosa. Belo Horizonte: Autêntica, 2004, pp. 151-166.

Quadros, R. M. O tradutor intérprete de Língua Brasileira de Sinais e Lingua Portuguesa. Secretaria de Educação Especial, Programa Nacional de Apoio à Educação de Surdos. Brasília: MEC; SEESP, 2004.

Rosa, A. S. Entre a visibilidade da tradução da língua de sinais e a invisibilidade da tarefa do intérprete. Dissertação (Mestrado) - Faculdade de Educação na Universidade Estadual de Campinas, SP, 2005.

Santos, S. A. Intérpretes de língua de sinais: um estudo sobre as identidades. Dissertação (Mestrado) - Faculdade de Educação. Florianópolis: Universidade Federal de Santa Catarina (UFSC), 2006.

SETTON, Maria da Graça; JACINTHO, Marcel Mauss; ELIAS, Norbert. Notas para uma aproximação epistemológica. Campinas: Educação \& Sociedade, v. 34, n. 122,2013 . p. 195-210.

Zuboff, Shoshana. "Big Other: capitalismo de vigilância e perspectivas para uma civilização de informação". Tecnopolíticas da vigilância: perspectivas da margem, organizado por Fernada Bruno [et al.]. Tradução: Heloísa Cardoso Mourão [et al.]. São Paulo: Boitempo, 2019.

Lucyenne Matos da Costa Vieira-Machado. E-mail: profaluvieiramachado@ gmail.com. https://orcid.org/0000-0002-7385-6243.

Cassio Pereira Oliveira. E-mail: cassio.tils@gmail.com. https://orcid.org/00000001-7243-8026.

Cad. Trad., Florianópolis, v. 41, $\mathrm{n}^{0}$ esp. 2, p. 273-302, ago/dez, 2021. 302 